\title{
Pea seed-borne mosaic virus in Field Pea: Widespread Infection, Genetic Diversity, and Resistance Gene Effectiveness
}

B. S. Congdon, School of Plant Biology and Institute of Agriculture, Faculty of Science, University of Western Australia, Crawley, WA 6009, Australia; B. A. Coutts, Crop Protection Branch, Department of Agriculture and Food Western Australia, Perth, WA 6983, Australia; M. Renton, School of Plant Biology and Institute of Agriculture, Faculty of Science, University of Western Australia; M. Banovic, Crop Protection Branch, Department of Agriculture and Food Western Australia; and R. A. C. Jones, Institute of Agriculture, Faculty of Science, University of Western Australia and Crop Protection Branch, Department of Agriculture and Food Western Australia

\begin{abstract}
Congdon, B. S., Coutts, B. A., Renton, M., Banovic, M., and Jones, R. A. C. 2016. Pea seed-borne mosaic virus in field pea: widespread infection, genetic diversity and resistance gene effectiveness. Plant Dis. 100:2475-2482.

From 2013 to 2015, incidences of Pea seed-borne mosaic virus (PSbMV) infection were determined in semi-leafless field pea (Pisum sativum) crops and trial plots growing in the Mediterranean-type environment of southwest Australia. PSbMV was found at incidences of 2 to $51 \%$ in 9 of 13 crops, 1 to $100 \%$ in 20 of 24 cultivar plots, and 1 to $57 \%$ in 14 of 21 breeding line plots. Crops and plots of 'PBA Gunyah', 'Kaspa', and 'PBA Twilight' were frequently PSbMV infected but none of PSbMV resistance gene sbml-carrying 'PBA Wharton' plants were infected. In 2015, 14 new PSbMV isolates obtained from these various sources were sequenced and their partial coat protein $(\mathrm{CP})$ nucleotide sequences analyzed. Sequence identities and phylogenetic comparison with 39 other PSbMV partial CP nucleotide sequences from GenBank demonstrated

that at least three PSbMV introductions have occurred to the region, one of which was previously unknown. When plants of 'Greenfeast' and PBA Gunyah pea (which both carry resistance gene $s b m 2$ ) and PBA Wharton and 'Yarrum' (which carry $s b m 1$ ) were inoculated with PSbMV pathotype P-2 isolate $\mathrm{W} 1$, resistance was overcome in a small proportion of plants of each cultivar, showing that resistance-breaking variants were likely to be present. An improved management effort by pea breeders, advisors, and growers is required to diminish infection of seed stocks, avoid sbm gene resistance being overcome in the field, and mitigate the impact of PSbMV on seed yield and quality. A similar management effort is likely to be needed in field pea production elsewhere in the world.
\end{abstract}

Pea seed-borne mosaic virus (PSbMV; family Potyviridae, genus Potyvirus) infects field pea (Pisum sativum), other types of pea, and several other legume crops in most cropping regions around the world. Sowing infected pea seed stocks produces infected plants scattered arbitrarily throughout the crop, which act as the primary inoculum source for plant-to-plant spread by aphid vectors in a nonpersistent manner throughout the growing season (e.g., Coutts et al. 2009; Khetarpal and Maury 1987) and wind-mediated contact transmission early in the growing season (Congdon et al. 2016). PSbMV causes substantial seed yield and quality losses in field pea, especially when the seed sown has infection levels $>0.5 \%$ and incidences reach high levels early in the life of the crop (Ali and Randles 1998; Coutts et al. 2008, 2009). However, despite the magnitude of such losses, the foliar symptoms caused by PSbMV infection in the field are often subtle and difficult to observe, such that the importance of PSbMV infection tends to be underestimated or its presence overlooked (Khetarpal and Maury 1987; Latham and Jones 2001b). Looking across the field pea crop canopy for depressions containing partially stunted pea plants, mostly centered on a seed-infected plant, often provides a better approach than close-up inspection for symptoms of PSbMV infection in individual plants (Coutts et al. 2009).

PSbMV isolates are classified biologically into four pathotypes which correspond to the responses of plants belonging to pea differentials carrying resistance genes $s b m 1, s b m l^{1}$, or $s b m 2$ to inoculation

Corresponding author: B. Congdon;

E-mail: benjamin.congdon@research.uwa.edu.au

*The $\boldsymbol{e}$-Xtra logo stands for "electronic extra" and indicates that one supplementary figure is published online.

Accepted for publication 20 July 2016.

http://dx.doi.org/10.1094/PDIS-05-16-0670-RE

(C) 2016 The American Phytopathological Society with the virus: $s b m 1$ confers resistance to pathotypes P-1 to P-4, $s b m 1^{1}$ (an allele of $s b m 1$ ) to pathotypes $\mathrm{P}-1$ and $\mathrm{P}-2$, and $s b m 2$ to pathotypes P-2 and P-3 (Gao et al. 2004; Makkouk et al. 2014). Isolates not distinguished by any of these differentials also occur and, therefore, fall outside pathotypes P-1 to P-4, such as those from the Indian subcontinent classified as pathotypes U-1 and U-2 (Ali and Randles 1997). Additionally, partial PSbMV resistance which seems polygenically controlled occurs in some pea genotypes (Coutts et al. 2008; Hampton 1980; Latham and Jones 2001b; van Leur et al. 2013). Pathotypes have differing levels of virulence and some still decrease seed yield despite causing symptomless infection (Ali and Randles 1998).

In the grain belt of southwest Australia, which has a Mediterraneantype climate, field pea is an important crop legume grown between late autumn and early spring (May to September). It is mainly sown in finely textured, neutral to alkaline soils, to which the predominant grain legume, narrow-leafed lupin (Lupinus angustifolius), is poorly adapted (Gladstones 1998; Siddique et al. 1999). Field pea is grown in rotation with wheat (Triticum aestivum) and canola (Brassica napus) crops, to which it provides several benefits, including nitrogen fixation and weed and fungal disease breaks (Evans et al. 1989; Siddique et al. 1999). No alternative weed or volunteer crop PSbMV hosts have been found (Latham and Jones 2001b). However, due to its seedborne nature in field pea, in Mediterranean-type environments, it is still able to persist effectively between growing seasons to infect rain-fed pea crops in the following growing season (Coutts et al. 2009). Sowing seed stocks with as little as $0.1 \%$ infection can cause seed yield losses in years of high PSbMV risk, when high presowing rainfall levels result in substantial migrant aphid numbers during the growing season (Coutts et al. 2009). In 1999, PSbMV was detected in field pea at incidences of 1 to $9 \%$ in 26 of 62 commercial crops and 0.1 to $10 \%$ in 10 of 16 commercial seed stocks (Latham and Jones 2001a). Cultivars sampled at that time consisted of conventional-leafed types such as 'Dundale', 'Magnet', 'Cooke', and 'Parafield', few of which are sown now. Such cultivars have gradually been replaced by semi-leafless types with improved performance traits, including increased yield 
and improved standing ability for ease of harvesting. In 2007, surveys of commercial seed stocks revealed 0.3 to $30 \%$ PSbMV infection in 33 of 33 semi-leafless 'Kaspa' and 0.5 to $47 \%$ in 12 of 12 conventionalleafed Parafield seed lots, indicating a substantial increase in infection (Coutts et al. 2008). However, no large-scale sampling of semi-leafless cultivar pea crops has been performed. Also, PSbMV pathotype P-2 is the only pathotype confirmed (isolate $\mathrm{W} 1$ ) to be present in southwest Australia (Wylie et al. 2011).

Field pea cultivars differ in PSbMV susceptibility, seed transmission rate, and yield and quality loss (Chiko and Zimmer 1978; Coutts et al. 2008; Kraft and Hampton 1980; Latham and Jones 2001b; Ovenden and Ashby 1981; van Leur et al. 2013; Wang et al. 1993). Therefore, it is important to monitor recently released cultivars to assess these characteristics so that losses can be foreseen and managed. In Australia, although partial PSbMV resistance was identified in some pea genotypes (e.g., Coutts et al. 2008; Latham and Jones 2001b) and presence of pathotypes P-1, P-2, and P-4 was confirmed (Wylie et al. 2011), no breeding for PSbMV resistance had been undertaken until recently (van Leur et al. 2013). Also, no research has been performed to establish which genomic regions confer partial PSbMV resistance or decrease symptom severity. Currently, the only cultivars with the comprehensive sbm1 PSbMV-resistance gene available are 'PBA Wharton' and 'Yarrum' (van Leur et al. 2013). PBA Wharton was only introduced in 2014 and Yarrum is generally unsuitable for southwest Australian growing conditions. The $s b m 2-$ carrying 'PBA Gunyah' (J. A. G. van Leur, personal communication) is currently sown in southwest Australia but the effectiveness of its resistance is yet to be evaluated fully.

This article describes studies designed to fill crucial knowledge gaps about PSbMV occurrence and genetic diversity and the effectiveness of $s b m$ resistance genes in the main pea production area of southwest Australia. First, PSbMV incidence data were obtained from (i) commercial field pea crops and seed stocks in 2015 and (ii) cultivar and breeding line trial plots in 2013 to 2015. Second, the nucleotide sequence diversity of the coat protein $(\mathrm{CP})$ gene of 14 new PSbMV isolates was evaluated. Third, the reaction to PSbMV inoculation of some currently grown field pea cultivars with or without $s b m 1$ and $s b m 2$ was determined.

\section{Materials and Methods}

Plants, sap inoculation, and virus cultures. All plants were maintained at 19 to $23^{\circ} \mathrm{C}$ in insect-proof air-conditioned glasshouses. For use as PSbMV culture hosts, plants of field pea Kaspa and 'PBA Twilight' and 'Fiord' faba bean (Vicia faba) were grown in a sand/ potting mix (50:50 blend). For use in experiments, healthy plants of semi-leafless field pea PBA Gunyah, Kaspa, PBA Twilight, PBA Wharton, and Yarrum, and conventional-leafed garden pea 'Greenfeast' were each grown individually in separate pots in the same sand/potting mix blend. For mechanical inoculations, $0.1 \mathrm{~g}$ of leaf material from systemically PSbMV-infected plants was ground

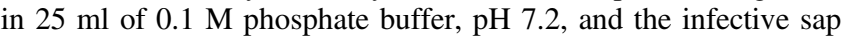
mixed with diatomaceous earth before being rubbed onto leaves. A culture of PSbMV isolate W1, obtained from infected pea in 1998 in southwest Australia (Latham and Jones 2001b), was maintained by serial mechanical inoculation to pea and faba bean plants. Isolate Kaspa was obtained from an infected field pea Kaspa plant grown from a 2010 seed lot and maintained temporarily by a single mechanical inoculation to healthy Kaspa plants. Infected leaf samples containing isolates W1 and Kaspa were used as PSbMV inoculum in the experiments. Leaf samples from pea or faba bean plants infected with isolate $\mathrm{W} 1$ were used as the positive control in enzyme-linked immunosorbent assay (ELISA). All plants were sprayed regularly with the insecticide imidacloprid $(0.125 \mathrm{~g} /$ liter $)$ to ensure that aphids were absent.

PSbMV incidence in field pea crops and plots. In 2015, 13 commercial field pea crops were sampled from five sites (Scaddan, West Scaddan, Beaumont, North Cascade, and Grass Patch) located in high (>450 mm per year), medium (325 to $450 \mathrm{~mm}$ ), or low (250 to $325 \mathrm{~mm}$ ) rainfall zones in the Esperance region of southwest Australia (Fig. 1). From each crop, 100 shoot tips, each taken from a separate plant, were collected by taking a single sample every five paces. Samples were collected in a V-shaped pattern starting $20 \mathrm{~m}$ inside the perimeter of each crop. Leaf samples from cultivar or breeding line trial plots (Australian National Variety Trial Program) were collected from sites in medium rainfall zones: Bolgart in 2013 and 2014, Muresk in 2015, and Grass Patch in 2013 to 2015. Shoot tips of 100 plants were collected across a single plot each of 'Bundi', 'Parafield', 'Percy', and 'Oura', and 21 breeding lines in 2013; from three to four plot replicates of PBA Gunyah, Kaspa, and PBA Twilight in 2013 to 2015; and from PBA Wharton in 2014 to 2015. Additionally, shoot tips of 100 Kaspa plants were collected in 2015 from one 50-by-50-m field trial block at Muresk. To attain a late PSbMV incidence value, sampling was done in early spring (late September), when crops or plots were at a late flowering stage or podding and beginning to senesce. All samples were tested for PSbMV individually by ELISA, except for PBA Wharton samples, which were tested in groups of 10. Representative seed samples from three commercial seed stocks sown in 2015 were tested for PSbMV transmission by ELISA. For this, seed was sown in trays and leaf samples from 1,000 seedlings were tested in groups of 10 by ELISA. Virus incidence from grouped sample tests was estimated using the formula of Gibbs and Gower (1960).

ELISA. To test for virus infection, leaf samples were extracted singly or in groups of $10(1 \mathrm{~g}$ per $20 \mathrm{ml})$ in $\mathrm{pH} 7.4$ phosphatebuffered saline $(10 \mathrm{mM}$ potassium phosphate, $150 \mathrm{mM}$ sodium chloride, Tween 20 at $5 \mathrm{ml} /$ liter, and polyvinyl pyrrolidone at $20 \mathrm{~g} / \mathrm{liter}$ ) using a mixer mill (Retsch). Sample extracts were tested for PSbMV by double-antibody sandwich ELISA (Clark and Adams 1977). The PSbMV polyclonal antiserum used was from DSMZ. All samples were tested in duplicate wells in microtiter plates. Sap from PSbMV-infected and healthy field pea leaf samples were always included in paired wells to provide positive and negative controls, respectively. The substrate was $p$-nitrophenyl phosphate at $1.0 \mathrm{mg} / \mathrm{ml}$ in diethanolamine, $\mathrm{pH} 9.8$, at $100 \mathrm{ml} / \mathrm{liter}$. Absorbance values at $405 \mathrm{~nm}$ were measured in a microplate reader (Bio-Rad Laboratories). Positive absorbance values were always at least 10 times those of the healthy sap.

RNA extraction, reverse-transcription polymerase chain reaction, and sequencing. In 2015, 14 new PSbMV isolates were obtained from field pea shoot tip samples, 1 each from (i) seven infected commercial crops growing at Grass Patch, North Cascade, Scaddan, and West Scaddan; (ii) six infected cultivar trial plots at Grass Patch and Muresk; and (iii) one field trial block at Muresk. Total RNA extraction was conducted with each isolate using a Qiagen RNeasy plant mini-kit according to the manufacturer's instructions. Reverse-transcription polymerase chain reaction (RT-PCR) was performed using a Qiagen OneStep RT-PCR Kit (Qiagen) and primers LegPotyF and LegPotyR (Webster et al. 2007). The resulting amplicons were sequenced directly with these primers by The Australian Genome Research Facility using an Applied Biosystems 3730 DNA analyzer with BigDye Terminator 3.1 chemistry producing partial $\mathrm{CP}$ gene nucleotide sequences that were analyzed using Geneious 8.0.5 (Biomatters). Final nucleotide sequences were submitted to the European Nucleotide Archive with accession numbers LT220180 to LT220193.

Sequence identities and phylogenetic analysis. The 14 new sequences were aligned with 12 Australian and 27 other (from nine countries in four continents) partial-length PSbMV CP sequences obtained from GenBank (Table 1) using Clustal W in MEGA 6.06 (Tamura et al. 2011). Average and pairwise comparisons of nucleotide percentage identities were calculated by dividing the number of differences by the sequence length, as determined in MEGA 6.06 using the pairwise deletion option and standard parameters. Phylogenetic analysis compared the 14 new PSbMV partial CP sequences from this study with (i) the 39 sequences obtained from GenBank, with all 53 trimmed to the length of the shortest sequence (400 nucleotides [nt]), and (ii) the 10 longest sequences from (i), with these 24 trimmed to the length of the shortest sequence (600 nt). Plum pox virus isolate $\mathrm{SoC}$ was used as an outgroup. Neighbor-joining trees were constructed using the number of differences model, maximum-likelihood 
trees using the Tamura-Nei model, and minimum-evolution trees using the number of differences model. A bootstrap value of 1,000 was used with all three models.

Cultivar reaction to PSbMV. In experiment 1, 10 healthy plants each of PBA Gunyah, Kaspa, PBA Twilight, and Yarrum were inoculated twice on two consecutive days with PSbMV isolate Kaspa, and 10 plants of each cultivar were mock-inoculated twice with healthy Kaspa sap at the same time (control). Experiment 2 was a repeat of experiment 1, except Greenfeast was also included. In experiment 3, 15 healthy field plants each of Greenfeast, PBA Gunyah, Kaspa, PBA Twilight, PBA Wharton, and Yarrum were inoculated twice on two consecutive days with PSbMV isolate W1, and 15 plants of each cultivar were mock-inoculated twice with healthy Kaspa sap at the same time (control). Experiment 4 was a repeat of experiment 3, except 30 plants of each cultivar were inoculated for each treatment. For each experiment, inoculum was used immediately after preparation and, within each experiment, always came from the same culture hosts. All plants were inoculated at the threeto four-node growth stage. To test for PSbMV infection, shoot tip samples from each plant were tested individually by ELISA 21 and 28 days after inoculation.

\section{Results}

PSbMV incidence in field pea crops and plots. In 2015, PSbMV incidences of 2 to $51 \%$ were detected in 9 of 13 commercial field pea crops at four of five locations (Table 2). The crops found infected were at Grass Patch, North Cascade, Scaddan, and West Scaddan. Of the PSbMV-infected crops sampled, five were PBA Gunyah, with incidences of 2 to 7\%; two were PBA Twilight, with incidences of 13 to $15 \%$; one was Kaspa, with $49 \%$ incidence; and one was Parafield, with $51 \%$ incidence. The four crops without infection were two each of PBA Gunyah at Beaumont and PBA Wharton at Grass Patch. When the samples of seed sown were tested for PSbMV seedborne infection, $0.6 \%$ was found for the Kaspa crop from West Scaddan, with a crop incidence of $49 \%$; $0.1 \%$ for the PBA Gunyah crop from Scaddan, with a crop incidence of $2 \%$; and $0.2 \%$ each in the two PBA Gunyah crops from Grass Patch, with crop incidences of 2 and 3\%, respectively.

From 2013 to 2015, PSbMV incidences of 1 to $100 \%$ and 1 to $57 \%$ were detected in 20 of 24 cultivar trial plots and 14 of 21 breeding line trial plots, respectively (Table 3 ). In each year of sampling, cultivar trial plots were found infected at Bolgart, Grass Patch, and Muresk. PSbMV incidences were 13 to $100 \%$ in Kaspa, 8 to $27 \%$ in PBA Twilight, and 1 to 52\% in PBA Gunyah. In cultivars sampled in 2013 only, PSbMV incidences were $100 \%$ in Parafield, $63 \%$ in Percy, $23 \%$ in Oura, and $1 \%$ in Bundi. All four of the cultivar trial plots without PSbMV infection were of PBA Wharton. In 21 breeding line trial plots at Bolgart in 2013, 14 had PSbMV incidences of 1 to $57 \%$ but no infection was found in 7 breeding lines.

Phylogenetic analysis and sequence identities. When the 14 new and 39 previously sequenced PSbMV CP isolate nucleotide sequences trimmed to $400 \mathrm{nt}$ were subjected to phylogenetic analysis, they clustered into three groups: subclades Ai and Aiii and clade $\mathrm{C}$ (Fig. 2). The new isolates from PBA Gunyah (NVTMG) and PBA Twilight (NVTMTL) trial plots at Muresk and PBA Gunyah trial plots at Grass Patch (NVTGPG) were genetically homogenous (100\% nucleotide identity). They fitted into clade Ai, which also included previously sequenced southwest Australian isolate W1,

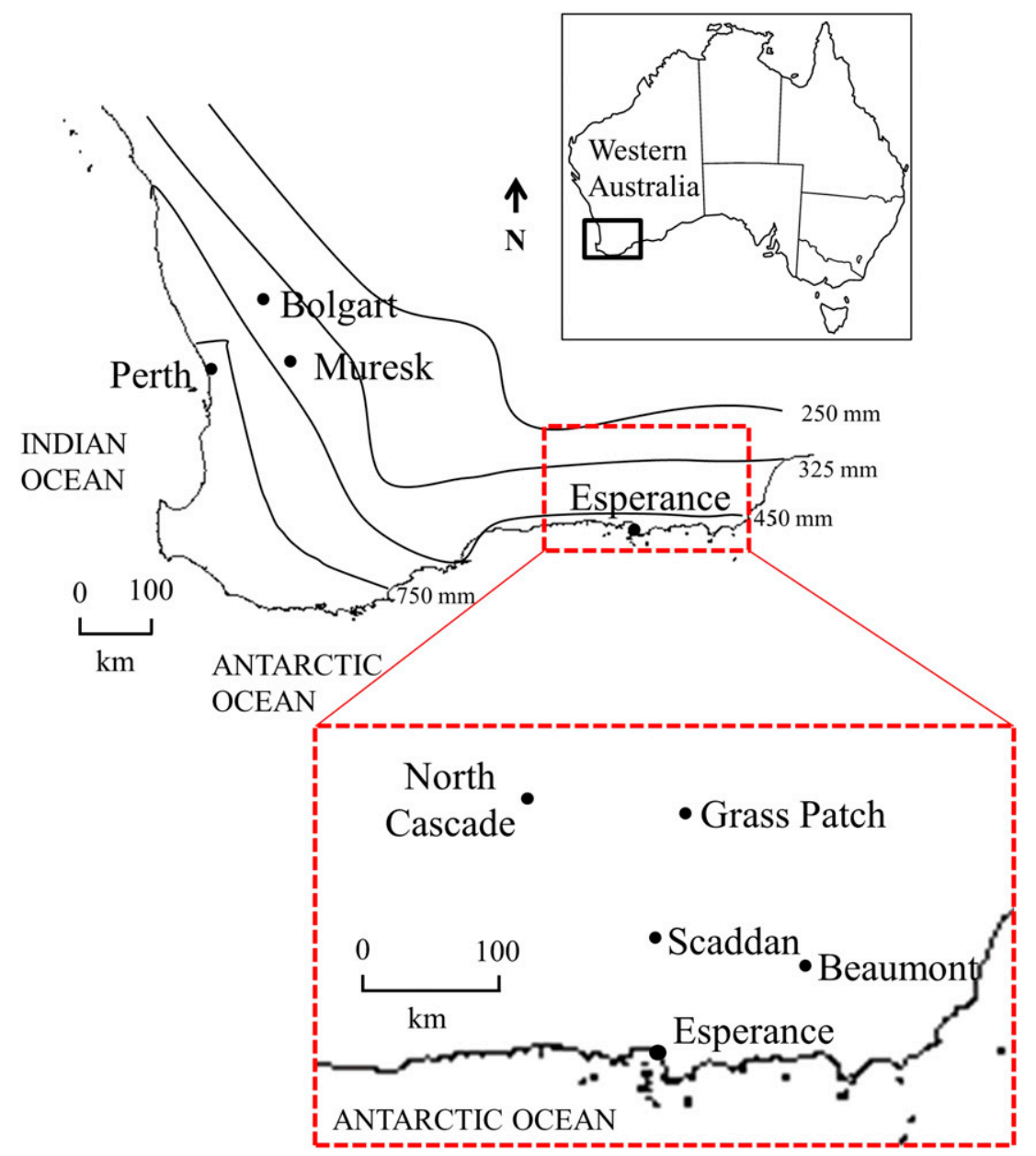

Fig. 1. Locations of commercial field pea crops sampled in 2015 and trial plots (Australian National Variety Trial Program) sampled in 2013 to 2015 in southwest Australia. Insert to the southwest Australian map shows locations sampled in the Esperance region. 
Table 1. Isolates of Pea seed-borne mosaic virus obtained from GenBank and used in coat protein nucleotide sequence comparisons

\begin{tabular}{|c|c|c|c|c|}
\hline Isolate & Geographical origin ${ }^{a}$ & Host & Pathotype $^{b}$ & Accession code \\
\hline $7-4.20$ & Wagga Wagga, NSW, Australia & Pea Bluey & P-1 & HQ185577 \\
\hline DPD $1^{\mathrm{c}}$ & Denmark & Pea & $\mathrm{P}-1$ & NC_001671 \\
\hline $\mathrm{NZ}$ & New Zealand & Pea & $\mathrm{P}-1$ & D10453 \\
\hline PSB117CZ & Czech Republic & Pea & P-1 & EU293758 \\
\hline PSB118CZ & Czech Republic & Pea & P-1 & EU293759 \\
\hline PSB141CZ & Czech Republic & Pea & P-1 & EU293760 \\
\hline PSB178CZ & Czech Republic & Pea & P-1 & EU293761 \\
\hline PSB329CZ & Czech Republic & Pea & P-1 & EU293762 \\
\hline PSBDCZ & Czech Republic & Pea & P-1 & EU293763 \\
\hline PSBECZ & Czech Republic & Pea & P-1 & EU293764 \\
\hline US & United States & N/A & P-1 & AF127768 \\
\hline PSbMV-28 & Rothamsted, United Kingdom & Pea & P-1 & AF023146 \\
\hline China1 & China & Faba bean & P-2 & HQ185580 \\
\hline W1 & Medina, WA, Australia & Pea & $\mathrm{P}-2$ & HQ185581 \\
\hline $7-6.19$ & Wagga Wagga, NSW, Australia & Pea & $\mathrm{P}-2$ & HQ185579 \\
\hline $\mathrm{L} 1^{\mathrm{c}}$ & Washington, United States & Lentil & $\mathrm{P}-2$ & AJ 252242 \\
\hline NEP1 & Nepal & Faba bean & P-3 & AJ311841 \\
\hline$N Y^{c}$ & New York, United States & Pea & $\mathrm{P}-4$ & X87938 \\
\hline $7-1.35$ & Ballarat, Vic, Australia & Pea Kaspa & P-4 & HQ185574 \\
\hline $7-2.33$ & NSW, Australia & Pea Kaspa & $\mathrm{P}-4$ & HQ185575 \\
\hline $7-3.26$ & Deniliquin, NSW, Australia & Pea Kaspa & $\mathrm{P}-4$ & HQ185576 \\
\hline $7-4.22$ & Wagga Wagga, NSW, Australia & Pea Bluey & P-4 & HQ185578 \\
\hline S6 & SA, Australia & Pea & $\mathrm{P}-4$ & AF127767 \\
\hline PSB58CZ & Czech Republic & Pea & $\mathrm{P}-4$ & EU293765 \\
\hline PK9 & Pakistan & N/A & $\mathrm{U}-2$ & AF127769 \\
\hline Idaho & Idaho, United States & N/A & N/A & U16215 \\
\hline $07 / 5088$ & Esperance, WA, Australia & Pea Kaspa & N/A & HQ185570 \\
\hline $07 / 5458$ & Esperance, WA, Australia & Pea Kaspa & N/A & HQ185571 \\
\hline $07 / 5772$ & Esperance, WA, Australia & Pea Kaspa & N/A & HQ185572 \\
\hline $07 / 6303$ & Esperance, WA, Australia & Pea Kaspa & N/A & HQ185573 \\
\hline WI-1 & Wisconsin, United States & Pea & N/A & AF023143 \\
\hline Can & Canada & N/A & N/A & Z48508 \\
\hline Egyptian & Egypt & Pea & N/A & AF522162 \\
\hline Ger & Germany & N/A & N/A & Z48509 \\
\hline WA-1 & Washington, United States & Pea & N/A & AF023144 \\
\hline Sv & Versailles, France & N/A & N/A & AF023151 \\
\hline PsP2 & Czech Republic & Pea & N/A & AF023145 \\
\hline EG-1 & N/A & N/A & N/A & AF023152 \\
\hline SL-25 & N/A & N/A & N/A & AF023147 \\
\hline PPV-SoC & Moldova & Prunus cerasus & $\ldots$ & X97398 \\
\hline
\end{tabular}

a WA = Western Australia, NSW = New South Wales, SA = South Australia, Vic = Victoria, and N/A = not available.

b Pathotype given where known.

${ }^{c}$ Complete genome sequence.

Table 2. Pea seed-borne mosaic virus incidences in 2015 and details of new isolates collected from field pea crops growing in the Esperance region of southwest Australia

\begin{tabular}{|c|c|c|c|c|c|c|}
\hline Cultivar & Location & $\begin{array}{l}\text { Infection }(\%) \\
\text { in seed sown }\end{array}$ & $\begin{array}{c}\text { Incidence (\%) } \\
\text { in crop }^{\mathbf{b}}\end{array}$ & $\begin{array}{c}\text { Isolate } \\
\text { name }\end{array}$ & $\begin{array}{c}\text { Sequence accession } \\
\text { number }\end{array}$ & $\begin{array}{l}\text { Phylogenetic } \\
\text { clade }^{d}\end{array}$ \\
\hline PBA Gunyah & Scaddan & - & 2 & DCG & LT220186 & Aiii \\
\hline PBA Gunyah & Scaddan & - & 7 & - & - & - \\
\hline PBA Gunyah & Scaddan & 0.1 & 2 & $\mathrm{KCG}$ & LT220187 & Aiii \\
\hline PBA Gunyah & Beaumont & - & 0 & - & - & - \\
\hline PBA Gunyah & Beaumont & - & 0 & - & - & - \\
\hline PBA Twilight & North Cascade & - & 15 & MATL & LT220189 & Aiii \\
\hline PBA Twilight & North Cascade & - & 13 & - & - & - \\
\hline PBA Wharton & Grass Patch & - & 0 & - & - & - \\
\hline PBA Wharton & Grass Patch & - & 0 & - & - & - \\
\hline PBA Gunyah & Grass Patch & 0.2 & 3 & RLG1 & LT220185 & Aiii \\
\hline PBA Gunyah & Grass Patch & 0.2 & 2 & RLG2 & LT220188 & Aiii \\
\hline Kaspa & West Scaddan & 0.6 & 49 & GRK & LT220180 & $\mathrm{C}$ \\
\hline Parafield & West Scaddan & - & 51 & GRPara & LT220181 & $\mathrm{C}$ \\
\hline
\end{tabular}

a For seed, 1,000 were grown in trays and samples from seedlings tested in groups of 10 by enzyme-linked immunosorbent assay (ELISA); - indicates sample not tested, no virus detected or isolate not sequenced.

${ }^{\mathrm{b}}$ For leaf samples, 100 were collected at late flowering or podding time and tested individually by ELISA, except with PBA Wharton, for which samples were tested in groups of 10 .

c Accession number in European Nucleotide Archive.

${ }^{\mathrm{d}}$ Clade from phylogenetic analysis. 
originally from Medina, Perth (99.7\% nucleotide identity), and 7.420 from New South Wales (99.7\% nucleotide identity). All new isolates from crops of PBA Gunyah from Scaddan (DCG and KCG) and Grass Patch (RLG1 and RLG2) and of PBA Twilight from North Cascade (MATL) were also all genetically homogenous (100\% nucleotide identity). They fitted into subclade Aiii, which previously had not included any sequenced southwest Australian isolates but included previously sequenced New South Wales isolate 7-6.19 (99.7\% nucleotide identity) and German isolate Ger (99.5\% nucleotide identity). New isolates from crops of Kaspa and Parafield from Scaddan (GRK and GRPara), the Kaspa field trial block from Muresk (ValMK), Kaspa trial plots at Grass Patch (NVTGPK) and Muresk (NVTMK), and PBA Twilight plots from cultivar trials at Grass Patch (NVTGPTL) were genetically homogenous
(98.7 to $100 \%$ nucleotide identity). They all fitted into clade C, which included previously sequenced southwest Australian isolates 7.5088, 7.5772, 7.5458, and 7.6303 from Esperance (99 to $99.7 \%$ nucleotide identity); 7-3.26, 7-4.22, and 7-2.33 from New South Wales (99 to $99.7 \%$ nucleotide identity); and 7-1.35 from Victoria (99 to $99.7 \%$ nucleotide identity). Subclade Ai contained previously sequenced isolates belonging to pathotypes P-1, P-2, and U-2; subclade Aii contained P-1 isolates; and subclade Aiii contained a P-2 isolate. Clade B contained a pathotype P-2 isolate and clade $\mathrm{C}$ contained isolates belonging to $\mathrm{P}-4$. When the $\mathrm{CP}$ nucleotide sequences of the 14 new isolates and 10 previously sequenced isolates with lengths $>600 \mathrm{nt}$ were trimmed to $600 \mathrm{nt}$ and analyzed, the new isolates fitted into the same groups as before (Supplementary Fig. S1).

Table 3. Pea seed-borne mosaic virus incidence and new isolates collected from field pea cultivar and breeding line plots growing in southwest Australia ${ }^{a}$

\begin{tabular}{|c|c|c|c|c|c|c|}
\hline Plots $^{\mathbf{b}}$ & Year collected & Location & Incidence $(\%)$ in plots & Isolate name & Sequence accession number ${ }^{c}$ & Clade $^{\text {d }}$ \\
\hline \multicolumn{7}{|l|}{ Cultivar } \\
\hline Parafield & 2013 & Bolgart & 100 & - & - & - \\
\hline Kaspa & 2013 & Bolgart & 93 & - & - & - \\
\hline PBA Twilight & 2013 & Bolgart & 23 & - & - & - \\
\hline PBA Gunyah & 2013 & Bolgart & 20 & - & - & - \\
\hline Percy & 2013 & Bolgart & 63 & - & - & - \\
\hline Oura & 2013 & Bolgart & 23 & - & - & - \\
\hline Bundi & 2013 & Bolgart & 1 & - & - & - \\
\hline Kaspa & 2014 & Bolgart & 100 & - & - & - \\
\hline PBA Twilight & 2014 & Bolgart & 27 & - & - & - \\
\hline PBA Gunyah & 2014 & Bolgart & 23 & - & - & - \\
\hline PBA Wharton & 2014 & Bolgart & 0 & - & - & - \\
\hline Kaspa & 2014 & Grass Patch & 13 & - & - & - \\
\hline PBA Twilight & 2014 & Grass Patch & 10 & - & - & - \\
\hline PBA Gunyah & 2014 & Grass Patch & 1 & - & - & - \\
\hline PBA Wharton & 2014 & Grass Patch & 0 & - & - & - \\
\hline Kaspa & 2015 & Muresk & 82 & NVTMK & LT220184 & $\mathrm{C}$ \\
\hline PBA Twilight & 2015 & Muresk & 26 & NVTMTL & LT220190 & $\mathrm{Ai}$ \\
\hline PBA Gunyah & 2015 & Muresk & 52 & NVTMG & LT220192 & $\mathrm{Ai}$ \\
\hline PBA Wharton & 2015 & Muresk & 0 & - & - & - \\
\hline Kaspa & 2015 & Grass Patch & 78 & NVTGPK & LT220183 & $\mathrm{C}$ \\
\hline PBA Twilight & 2015 & Grass Patch & 8 & NVTGPTL & LT220182 & $\mathrm{C}$ \\
\hline PBA Gunyah & 2015 & Grass Patch & 5 & NVTGPG & LT220191 & $\mathrm{Ai}$ \\
\hline PBA Wharton & 2015 & Grass Patch & 0 & - & - & - \\
\hline Kaspa & 2015 & Muresk & 57 & ValMK & LT220193 & $\mathrm{C}$ \\
\hline \multicolumn{7}{|l|}{ Breeding line } \\
\hline OZP1202 & 2013 & Bolgart & 57 & - & - & - \\
\hline OZP1206 & 2013 & Bolgart & 40 & - & - & - \\
\hline OZP1210 & 2013 & Bolgart & 37 & - & - & - \\
\hline OZP1208 & 2013 & Bolgart & 27 & - & - & - \\
\hline OZP1101 & 2013 & Bolgart & 20 & - & - & - \\
\hline OZP1311 & 2013 & Bolgart & 20 & - & - & - \\
\hline OZP1302 & 2013 & Bolgart & 17 & - & - & - \\
\hline OZP1301 & 2013 & Bolgart & 13 & - & - & - \\
\hline OZP1304 & 2013 & Bolgart & 13 & - & - & - \\
\hline OZP1308 & 2013 & Bolgart & 10 & - & - & - \\
\hline OZP1309 & 2013 & Bolgart & 7 & - & - & - \\
\hline OZP1310 & 2013 & Bolgart & 7 & - & - & - \\
\hline OZP1306 & 2013 & Bolgart & 2 & - & - & - \\
\hline OZP1001 & 2013 & Bolgart & 1 & - & - & - \\
\hline OZP1305 & 2013 & Bolgart & 0 & - & - & - \\
\hline OZP0903 & 2013 & Bolgart & 0 & - & - & - \\
\hline WAPEA2211 & 2013 & Bolgart & 0 & - & - & - \\
\hline OZP1104 & 2013 & Bolgart & 0 & - & - & - \\
\hline OZP1209 & 2013 & Bolgart & 0 & - & - & - \\
\hline OZP1307 & 2013 & Bolgart & 0 & - & - & - \\
\hline OZP1303 & 2013 & Bolgart & 0 & - & - & - \\
\hline
\end{tabular}

a Symbol - indicates isolate unavailable or not sequenced.

${ }^{\mathrm{b}}$ For cultivar plots, 100 leaf samples from three to four replicate plots were tested individually by enzyme-linked immunosorbent assay (ELISA), except Kaspa (infected with isolate ValMK), where the 100 samples came from a single field trial block. For breeding line plots, 100 leaf samples from one breeding line plot were tested individually by ELISA.

${ }^{\mathrm{c}}$ Accession number in European Nucleotide Archive.

${ }^{\mathrm{d}}$ Clade from phylogenetic analysis. 
Cultivar reaction to PSbMV. Following double inoculation with isolate Kaspa in experiments 1 and 2, PSbMV was detected in shoot tip samples from 9 of 10 to 10 of 10 Kaspa plants and 5 of 10 to 8 of 10 PBA Twilight plants (Table 4). No infection was detected in shoot tip samples from Greenfeast, PBA Gunyah, and Yarrum in either experiment. Following double inoculation with isolate $\mathrm{W} 1$ in experiments 3 and 4, PSbMV was detected in shoot tip samples of 13 of 15 and 21 of 30 Kaspa and 5 of 15 and 16 of 30 PBA Twilight plants.

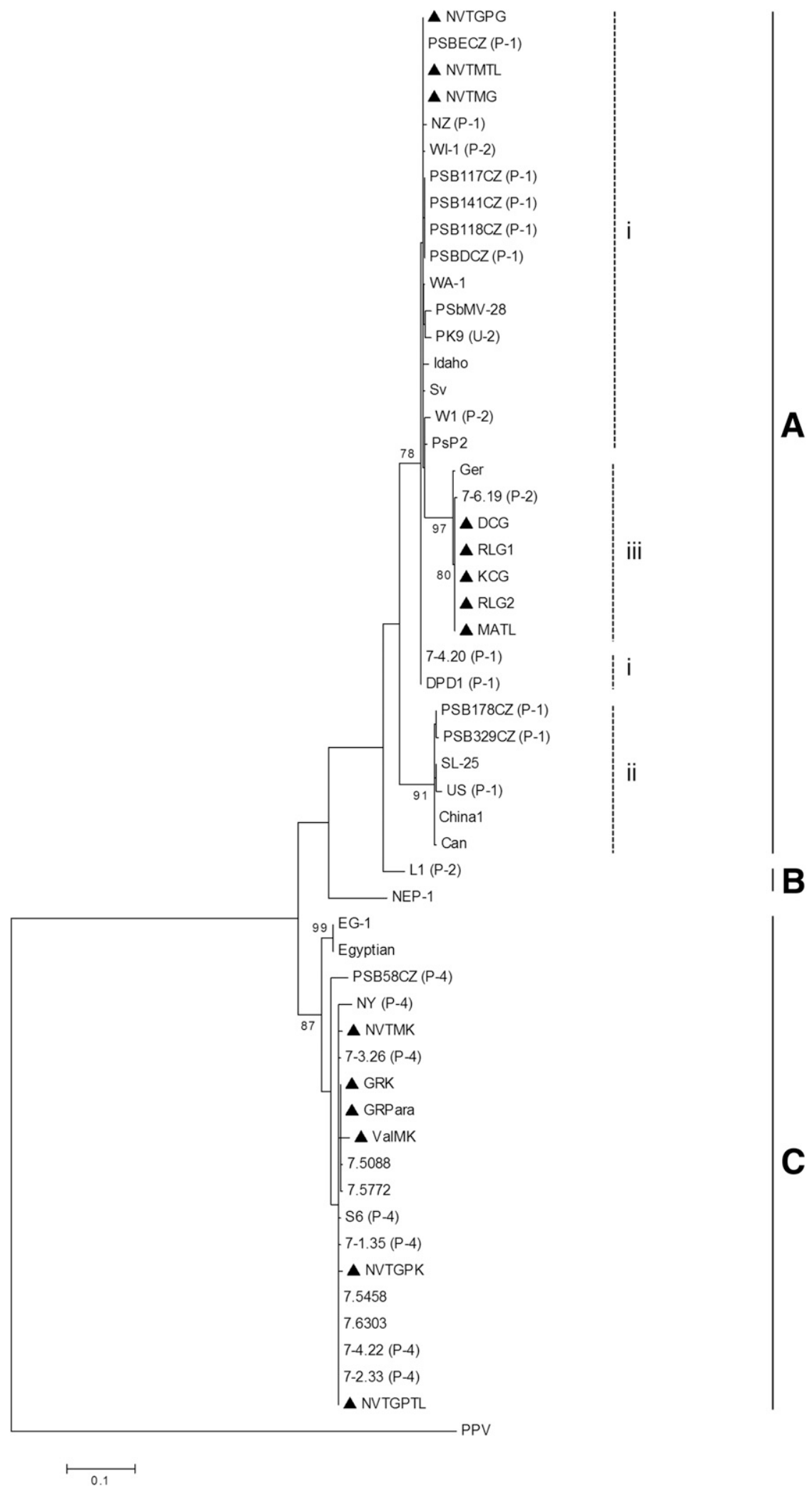

Fig. 2. Phylogenetic relationships among the nucleotide sequences of partial coat protein (CP) genes of 53 Pea seed-borne mosaic virus isolates. CP gene sequences of 14 new isolates and 39 previously sequenced isolates obtained from GenBank trimmed to 400 nucleotides in length. New isolates from this study are denoted with the symbol $\mathbf{\Lambda}$. The tree was inferred using maximum-likelihood based on calculations from the Tamura-Nei model, with a bootstrap value of 1,000. Numbers at nodes indicate bootstrap scores $>50 \%$. Branch lengths indicate the number of substitutions per site. Isolate SoC of Plum pox virus (PPV) was used as an outgroup. Where known, the pathotype each isolate belongs to is shown in parentheses beside the isolate name. 
Infection was also detected in shoot tip samples of 2 of 15 and 0 of 30 Greenfeast, 1 of 15 and 2 of 30 PBA Gunyah, 1 of 15 and 1 of 30 PBA Wharton, and 1 of 15 and 1 of 30 Yarrum plants. PSbMVinfected plants in all experiments were slightly stunted, with leaf curling and chlorosis. No infection was detected in mock-inoculated plants in any experiment.

\section{Discussion}

This study revealed far higher PSbMV incidences in field pea crops and plots growing in southwest Australia in 2013 to 2015 than those found previously in a survey undertaken in 1999 in the same region (Latham and Jones 2001a). This difference coincided with a change from growing conventional-leafed to semi-leafless field pea types, principally PBA Gunyah, Kaspa, and PBA Twilight. Phylogenetic analysis of partial CP nucleotide sequences of 14 new PSbMV isolates showed they belonged to three distinct phylogenetic groupings, demonstrating that a third introduction (subclade Aiii) to the region has occurred since the two identified previously (Wylie et al. 2011). This introduction was mostly likely from sowing seed of PBA Gunyah and PBA Twilight since their commercial release in 2011. Continued surveillance of further pea germplasm entering the region is required to prevent additional introductions of distinct PSbMV strains. When isolate W1 was inoculated to Greenfeast and PBA Gunyah, which carry resistance gene $s b m 2$, and PBA Wharton and Yarrum, carrying resistance gene $s b m 1$, these resistances were overcome in a small proportion of inoculated plants. This suggests that the combination of increased PSbMV genetic diversity and selection pressure arising from growing cultivars with $s b m 1$ or $s b m 2$ is likely to cause single-gene resistance to be overcome in the field. These findings in southwest Australia are likely to have broad implications for field pea production worldwide regarding the need to improve PSbMV management in breeding programs and healthy seed production, and avoid inadvertent introduction and distribution of PSbMV strains that overcome sbm resistance genes.

PSbMV infection was detected in commonly sown field pea cultivars at six of seven locations sampled. The high PSbMV incidences found in PBA Gunyah (0 to 52\%), Kaspa (49 to 100\%), and PBA Twilight (3 to 27\%) suggests widespread PSbMV contamination of seed stocks sown. For Kaspa, this was not unexpected because PSbMV incidences of 0.5 to $47 \%$ were detected previously in commercial seed stocks (Coutts et al. 2008). This cultivar is better suited to growing in higher rainfall zones than PBA Gunyah or PBA Twilight (Pritchard 2014). However, as mentioned above, levels of $>0.5 \%$ PSbMV infection in Kaspa seed lots can result in substantial seed yield and quality losses in a high-risk year (Coutts et al. 2009), which tends to negate the yield benefits obtained from growing it in higher rainfall zones. The relationship between percent PSbMV infection in seed sown, crop incidence, and yield loss is illustrated by two commercial seed lots of PBA Gunyah and Kaspa, both sown simultaneously at the same location. These had seedborne infection levels of $0.1 \%$ (PBA Gunyah) and $0.6 \%$ (Kaspa) resulting in crop incidences of 2 and $49 \%$ at flowering time, respectively. Consequently, PSbMV-induced yield losses would be expected to have been substantial in the Kaspa crop but negligible in the PBA Gunyah crop.

Comparison of PSbMV CP nucleotide sequences available from GenBank with nucleotide sequences from this study allowed a snapshot of the current PSbMV genetic diversity present in the southwest Australian grain belt. Previous phylogenetic analysis indicated two PSbMV introductions with isolates in subclade $\mathrm{Ai}$ and clade $\mathrm{C}$ (Wylie et al. 2011). Because one isolate from PBA Twilight and four from PBA Gunyah fitted into subclade Aiii, our analysis demonstrated that another introduction has occurred to the region. Moreover, sowing annual cultivar and breeding line trial plots with infected seed originating from field pea breeding programs at multiple sites around Australia is a likely contributor to increased PSbMV genetic diversity. Phylogenetic analysis indicates that the 14 new PSbMV isolates potentially belong to pathotypes $\mathrm{P}-1, \mathrm{P}-2$, or P-4 because they fitted into either of subclades Ai or Aii or clade $\mathrm{C}$ (Wylie et al. 2011). However, the relationship between CP nucleotide sequence and pathotype groupings based on resistance gene reactions is insufficiently clear to be sure. To establish pathotypes, the new isolates would need to be tested for reactions following inoculation to plants of pea differentials carrying $s b m$ genes (e.g., Makkouk et al. 2014; Provvidenti and Alconero 1988). Moreover, complete genome sequencing along with use of biological data are needed to provide more information on phylogeny and whether any relationship exists between it and biological properties (Jones and Kehoe 2016; Kehoe and Jones 2016; Kehoe et al. 2014).

As mentioned earlier, the $s b m 2$ gene confers resistance to PSbMV pathotype P-2, previously identified in southwest Australia (Wylie et al. 2011), and P-3, which has only been reported in faba bean in Nepal (Hjulsager et al. 2002). Incidences of up to $3 \%$ in crops and $52 \%$ in trial plots of PBA Gunyah were found in the region, suggesting the presence of pathotypes P-1 or P-4. It is likely that strains belonging to pathotype $\mathrm{P}-2$, and another pathotype to which PBA Gunyah is susceptible, are present in the trial plots. This may account for the low PSbMV incidences sometimes found in plots growing in close proximity to plots of other cultivars with high incidences.

When inoculated with PSbMV isolate Kaspa, no plants of Greenfeast, PBA Gunyah, and Yarrum carrying single-gene resistance became infected. However, when plants of these cultivars and PBA Wharton were inoculated with isolate $\mathrm{W} 1$, resistance was overcome, because a small proportion of plants of each cultivar became infected. Greenfeast and PBA Gunyah carry sbm2, isolate Kaspa, and the majority of the virus population within $\mathrm{W} 1$ belong to pathotype P-2. However, despite being predominantly pathotype P-2, a low level of isolate W1 infection was found not only in Greenfeast and PBA Gunyah but also in PBA Wharton and Yarrum which, as mentioned above, carry sbml, conferring resistance to pathotypes P1 to P4 (van Leur et al. 2013). The high disease pressure associated with mechanical inoculation exposes plants to a broader swarm of variants than the bottleneck effect imposed on virus populations during aphid and seed transmission (Fabre et al. 2014; Moury et al. 2007). Since it was first isolated in 1998, isolate W1 was maintained for 12 years via serial mechanical inoculation; therefore, it would be expected to consist of a wider range of variants than isolate Kaspa as described by Fabre et al. (2014), which was obtained directly from a seed-infected plant. Therefore, the selection pressure arising from $\mathrm{sbm}$ gene resistance would be more likely to select a variant able to overcome $\mathrm{sbm} 1$ or sbm2 from isolate W1 than from isolate Kaspa. Alternatively, the failure to detect variants with isolate Kaspa might reflect the smaller number of plants inoculated with it. Whichever is the case, selection pressure arising from increased use of PSbMV-resistant PBA Wharton in the region would increase the potential of PSbMV to overcome $s b m 1$. However, in the field component of this study, no infection was detected in crops or plots of PBA Wharton, suggesting that it is still effective against PSbMV strains currently widespread in the region. Continued monitoring of PSbMV isolates may result in identification of new resistance-breaking strains, strains that cause yield

Table 4. Pea seed-borne mosaic virus detection in plants of five field pea cultivars with or without single-gene resistances following mechanical inoculation with two isolates

\begin{tabular}{|c|c|c|c|c|c|c|c|c|c|}
\hline \multirow[b]{4}{*}{ Cultivar } & \multirow[b]{4}{*}{ Gene } & \multicolumn{8}{|c|}{ Isolate $^{\mathbf{a}}$} \\
\hline & & \multicolumn{4}{|c|}{ Kaspa } & \multicolumn{4}{|c|}{ W1 } \\
\hline & & \multicolumn{2}{|c|}{ Exp. 1} & \multicolumn{2}{|c|}{ Exp. 2} & \multicolumn{2}{|c|}{ Exp. 3} & \multicolumn{2}{|c|}{ Exp. 4} \\
\hline & & VI & MI & VI & MI & VI & MI & VI & MI \\
\hline Kaspa & - & $9 / 10$ & $0 / 10$ & $10 / 10$ & $0 / 10$ & $13 / 15$ & $0 / 15$ & $21 / 30$ & $0 / 30$ \\
\hline PBA Twilight & - & $5 / 10$ & $0 / 10$ & $8 / 10$ & $0 / 10$ & $5 / 15$ & $0 / 15$ & $16 / 30$ & $0 / 30$ \\
\hline PBA Gunyah & $\operatorname{sbm} 2$ & $0 / 10$ & $0 / 10$ & $0 / 10$ & $0 / 10$ & $1 / 15$ & $0 / 15$ & $1 / 30$ & $0 / 30$ \\
\hline Greenfeast & $\operatorname{sbm} 2$ & - & - & $0 / 10$ & $0 / 10$ & $2 / 15$ & $0 / 15$ & $0 / 30$ & $0 / 30$ \\
\hline PBA Wharton & $s b m 1$ & - & - & - & - & $1 / 15$ & $0 / 15$ & $1 / 30$ & $0 / 30$ \\
\hline Yarrum & $s b m 1$ & $0 / 10$ & $0 / 10$ & $0 / 10$ & $0 / 10$ & $1 / 15$ & $0 / 15$ & $1 / 30$ & $0 / 30$ \\
\hline
\end{tabular}

a Newly emerged leaf samples from all plants were tested by enzyme-linked immunosorbent assay individually up to 28 days after inoculation. Control plants mock-inoculated with healthy Kaspa sap. Experiment (Exp.) 2 was a duplicate of Exp. 1, and Exp. 4 was a duplicate of Exp. 3. VI = virus inoculated and $\mathrm{MI}=$ mock-inoculated. Data shown are number of PSbMV-infected plants/ total number of plants; - indicates no resistance gene present or not tested. 
losses despite lack of symptom expression (Ali and Randles 1998), and other pathotypes such as U-1 and U-2 (Ali and Randles 1997), should they become introduced inadvertently. An additional finding from this study was that PBA Twilight plants were only moderately susceptible when inoculated with both PSbMV isolates. This suggests that PBA Twilight has partial resistance despite lacking $s b m$ resistance genes. Such partial resistance was demonstrated previously in other locally grown field pea cultivars (Coutts et al. 2008; Latham and Jones 2001b).

The widespread occurrence of PSbMV infection in commercial crops, and cultivar and breeding line trial plots, of field pea in the southwest Australian grain belt suggests the need for an increased awareness of PSbMV among pea breeders and a renewed effort to manage the virus more effectively. Not only is the release of new cultivars with high seedborne infection levels undesirable for production but also yield data from cultivar and breeding line trial plot sites are likely to be compromised due to PSbMV-induced losses not being taken into account. To help account for such errors, yield losses from PSbMV in each cultivar and breeding line would need to be estimated after testing seed samples prior to planting and leaf samples around flowering time to establish PSbMV incidence (Coutts et al. 2009). A loss adjustment could then be made to their final yields to calculate what values would be expected in the absence of PSbMV infection. There is an urgent need to reduce PSbMV infection levels in commercial seed stocks of locally adapted, higher-yielding field pea cultivars. In high-risk years, sowing seed lots of PBA Gunyah, Kaspa, and PBA Twilight with $>0.5 \%$ PSbMV infection could result in substantial yield losses. Moreover, PSbMV incidences in commercial seed stocks of newer cultivars such as PBA Gunyah and PBA Twilight are likely to amplify following resowing over multiple years. An increased effort toward obtaining and sowing seed with $<0.5 \%$ infection is vital in limiting spread and maintaining healthy seed stocks of these cultivars. This would be preferable to sowing sbm1-carrying PBA Wharton or Yarrum, especially when they are less suited to local conditions. Also, using $s b m l$-carrying cultivars nonprophylactically would decrease the potential for resistancebreaking strains to develop and become widespread. Quantifying the likely effect of climatic conditions on aphid population buildup and subsequent PSbMV spread would support management decisions such as cultivar choice and the need to source healthy seed and deploy cultural control measures (Congdon et al. 2014; Coutts et al. 2009). Further research is needed to deliver a forecasted risk rating specific to each pea-growing district. Similar research is likely to be required in many other field pea production regions worldwide where PSbMV-induced losses are not being taken into account.

\section{Acknowledgments}

This research was funded by Australian Research Council Linkage Project LP120200224, The University of Western Australia, and the Department of Agriculture and Food Western Australia (DAFWA). The experiments were undertaken using the South Perth glasshouse and laboratory facilities of DAFWA. We thank Esperance region field pea growers for allowing B. S. Congdon access to their crops; M. A. Kehoe for advice on RNA extraction, RT-PCR, and phylogenetic analysis; and B. E. Gajda for assistance with maintaining plants and PSbMV cultures in the glasshouse.

\section{Literature Cited}

Ali, A., and Randles, J. W. 1997. Early season survey of pea viruses in Pakistan and the detection of two new pathotypes of pea seedborne mosaic potyvirus. Plant Dis. 81:343-347.

Ali, A., and Randles, J. W. 1998. The effects of two pathotypes of pea seed-borne mosaic virus on the morphology and yield of pea. Australas. Plant Pathol. 27:226-233.

Chiko, A. W., and Zimmer, R. C. 1978. Effect of pea seed-borne mosaic virus on two cultivars of field pea grown in Manitoba. Can. J. Plant Sci. 58:1073-1077.

Clark, M. F., and Adams, A. N. 1977. Characteristics of the microplate method of enzyme-linked immunosorbent assay for the detection of plant viruses. J. Gen. Virol. 34:475-483.

Congdon, B. S., Coutts, B. A., Renton, M., and Jones, R. A. C. 2016. Pea seedborne mosaic virus: Stability and wind-mediated contact transmission in field pea. Plant Dis. 100:953-958.

Congdon, B. S., Renton, M., Coutts, B. A., Van Leur, J. A. G., and Jones, R. A. C. 2014. Understanding, managing and forecasting Pea seed-borne mosaic virus in field pea (Abstr.). Page 34 in: Proc. 11th Australas. Plant Virol. Workshop, Brisbane, Australia.
Coutts, B. A., Prince, R. T., and Jones, R. A. C. 2008. Further studies on Pea seedborne mosaic virus in cool-season crop legumes: Responses to infection and seed quality defects. Aust. J. Agric. Res. 59:1130-1145.

Coutts, B. A., Prince, R. T., and Jones, R. A. C. 2009. Quantifying effects of seedborne inoculum on virus spread, yield losses, and seed infection in the Pea seed-borne mosaic virus-field pea pathosystem. Phytopathology 99:1156-1167.

Evans, J., O’Connor, G., Turner, G., Coventry, D., Fettell, N., Mahoney, J., Armstrong, E., and Walsgott, D. 1989. $\mathrm{N}_{2}$ fixation and its value to soil $\mathrm{N}$ increase in lupin, field pea and other legumes in south-eastern Australia. Aust. J. Agric. Res. 40:791-805

Fabre, F., Moury, B., Johansen, E. I., Simon, V., Jacquemond, M., and Senoussi, R. 2014. Narrow bottlenecks affect Pea seedborne mosaic virus populations during vertical seed transmission but not during leaf colonization. PLoS Pathog. 10:e1003833.

Gao, Z., Johansen, I. E., Eyers, S., Thomas, C. L., Ellis, T. H. N., and Maule, A. J. 2004. The potyvirus recessive resistance gene, $s b m 1$, identifies a novel role for translation initiation factor eIF4E in cell-to-cell trafficking. Plant J. 40:376-385.

Gibbs, A. J., and Gower, J. C. 1960. The use of a multiple-transfer method in plant virus transmission studies-Some statistical points arising in the analysis of results. Ann. Appl. Biol. 48:75-83.

Gladstones, J. S. 1998. Distribution, origin, taxonomy, history and importance. Pages 1-40 in: Lupins as Crop Plants-Biology, Production and Utilization. J. S. Gladstones, C. Atkins, and J. Hamblin, eds. Cambridge University Press, Cambridge, UK

Hampton, R. O. 1980. Pea seedborne mosaic symptom variation among Pisum plant introduction accessions: Expressions and variation in symptom expression among different genotypes of Pisum and pathological implications. Pisum Newsl. 12:29-30.

Hjulsager, C. K., Sogaard Lund, O., and Johansen, I. E. 2002. A new pathotype of $P e a$ seedborne mosaic virus explained by properties of the p3-6k1- and viral genomelinked protein (VPg)-coding regions. Mol. Plant-Microbe Interact. 15:169-171.

Jones, R. A. C., and Kehoe, M. A. 2016. A proposal to rationalize within-species plant virus nomenclature: Benefits and implications of inaction. Arch. Virol. 161:2051-2057.

Kehoe, M. A., Coutts, B. A., Buirchell, B. J., and Jones, R. A. C. 2014. Plant virology and next generation Sequencing: Experiences with a Potyvirus. PLoS One 9:e104580.

Kehoe, M. A., and Jones, R. A. C. 2016. Improving Potato virus Y strain nomenclature: Lessons from comparing isolates obtained over a 73-year period. Plant Pathol. 65:322-333.

Khetarpal, R. K., and Maury, Y. 1987. Pea seed-borne mosaic virus: A review. Agronomie 7:215-224.

Kraft, J. M., and Hampton, R. O. 1980. Crop losses from pea seedborne mosaic virus in six processing pea cultivars. Plant Dis. 64:922-924.

Latham, L. J., and Jones, R. A. C. 2001a. Incidence of virus infection in experimental plots, commercial crops, and seed stocks of cool season crop legumes. Aust. J. Agric. Res. 52:397-413.

Latham, L. J., and Jones, R. A. C. 2001b. Alfalfa mosaic and pea seed-borne mosaic viruses in cool season crop, annual pasture, and forage legumes: Susceptibility, sensitivity, and seed transmission. Aust. J. Agric. Res. 52:771-790.

Makkouk, K. M., Kumari, S. G., van Leur, J. A., and Jones, R. A. C. 2014. Control of plant virus diseases in cool-season grain legume crops. Adv. Virus Res. 90:207-253.

Moury, B., Fabre, F., and Senoussi, R. 2007. Estimation of the number of virus particles transmitted by an insect vector. Proc. Natl. Acad. Sci. USA 104: 17891-17896.

Ovenden, G. E., and Ashby, J. W. 1981. The effect of pea seed-borne mosaic virus on yield of peas. Pages 61-63 in: Proc. Annu. Conf. Agron. Soc. N. Z., Massey University, New Zealand.

Pritchard, I. 2014. Field pea varieties for Western Australia: 2014. Online publication. Department of Agriculture and Food, Western Australia, Australia https://www.agric.wa.gov.au/field-peas/field-pea-varieties-western-australia2014

Provvidenti, R., and Alconero, R. 1988. Inheritance of resistance to a third pathotype of pea seed-borne mosaic virus in Pisum sativum. J. Hered. 79:76-77.

Siddique, K. H. M., Loss, S. P., Regan, K. L., and Jettner, R. L. 1999. Adaptation and seed yield of cool season grain legumes in Mediterranean environments of south-western Australia. Aust. J. Agric. Res. 50:375-388.

Tamura, K., Peterson, D., Peterson, N., Stecher, G., Nei, M., and Kumar, S. 2011 MEGA5: Molecular evolutionary genetics analysis using maximum likelihood, evolutionary distance, and maximum parsimony methods. Mol. Biol. Evol. 28: 2731-2739.

van Leur, J. A. G., Kumari, S. G., Aftab, M., Leonforte, A., and Moore, S. 2013. Virus resistance of Australian pea (Pisum sativum) varieties. N. Z. J. Crop Hortic. 41:86-101.

Wang, D., Woods, R. D., Cockbain, A. J., Maule, A. J., and Biddle, A. J. 1993. The susceptibility of pea cultivars to pea seed-borne mosaic virus infection and virus seed transmission in the UK. Plant Pathol. 42:42-47.

Webster, C. G., Coutts, B. A., Jones, R. A. C., Jones, M. G. K., and Wylie, S. J. 2007. Virus impact at the interface of an ancient ecosystem and a recent agroecosystem: Studies on three legume-infecting potyviruses in the southwest Australian floristic region. Plant Pathol. 56:729-742.

Wylie, S. J., Coutts, B. A., and Jones, R. A. C. 2011. Genetic variability of the coat protein sequence of Pea seed-borne mosaic virus isolates and the current relationship between phylogenetic placement and resistance groups. Arch Virol. 156:1287-1290. 